\title{
Developing Brain Glucose Transporters, Serotonin, Serotonin Transporter, and Oxytocin Receptor Expression in Response to Early-Life Hypocaloric and Hypercaloric Dietary, and Air Pollutant Exposures
}

\author{
Xin Ye Bo-Chul Shin Claire Baldauf Amit Ganguly Shubhamoy Ghosh \\ Sherin U. Devaskar \\ Department of Pediatrics, Division of Neonatology \& Developmental Biology and the Neonatal Research \\ Center of the UCLA Children's Discovery \& Innovation Institute, David Geffen School of Medicine at UCLA, \\ Los Angeles, CA, USA
}

\author{
Keywords \\ Environmental exposure · Fetal brain · Intrauterine growth \\ restriction · Neurodevelopment · Neurotransmitters
}

\begin{abstract}
Perturbed maternal diet and prenatal exposure to air pollution (AP) affect the fetal brain, predisposing to postnatal neurobehavioral disorders. Glucose transporters (GLUTs) are key in fueling neurotransmission; deficiency of the neuronal isoform GLUT3 culminates in autism spectrum disorders. Along with the different neurotransmitters, serotonin (5-HT) and oxytocin (OXT) are critical for the development of neural connectivity. Serotonin transporter (SERT) modulates synaptic 5-HT levels, while the OXT receptor (OXTR) mediates OXT action. We hypothesized that perturbed brain GLUT1/GLUT3 regulated 5-HT-SERT imbalance, which serves as a contributing factor to postnatal neuropsychiatric phenotypes, with OXT/OXTR providing a counterbalance. Employing maternal diet restriction (intrauterine growth restriction [IUGR]), highfat (HF) dietary modifications, and prenatal exposure to sim-
\end{abstract}

ulated AP, fetal (E19) murine brain 5-HT was assessed by ELISA with SERT and OXTR being localized by immunohistochemistry and measured by quantitative Western blot analysis. IUGR with lower head weights led to a $48 \%$ reduction in male and female fetal brain GLUT3 with no change in GLUT1, when compared to age- and sex-matched controls, with no significant change in OXTR. In addition, a 50\% ( $p=$ 0.005 ) decrease in 5-HT and SERT concentrations was displayed in fetal IUGR brains. In contrast, despite emergence of microcephaly, exposure to a maternal HF diet or AP caused no significant changes. We conclude that in the IUGR during fetal brain development, reduced GLUT3 is associated with an imbalanced 5-HT-SERT axis. We speculate that these early changes may set the stage for altering the 5HT-SERT neural axis with postnatal emergence of associated neurodevelopmental disorders.

(c) 2021 The Author(s)

Published by S. Karger AG, Basel

Xin Ye and Bo-Chul Shin equal contributors to the work cited in this manuscript.
(C) 2021 The Author(s)

Published by S. Karger AG, Basel

This is an Open Access article licensed under the Creative Commons Attribution-NonCommercial-4.0 International License (CC BY-NC) (http://www.karger.com/Services/OpenAccessLicense), applicable to the online version of the article only. Usage and distribution for commercial purposes requires written permission.
Sherin U. Devaskar

Pediatrics/Neonatology and Developmental Biology and Neonatal Research Center David Geffen School of Medicine, University of California

10833 Le Conte Ave., Los Angeles, CA 90095-1752 (USA) sdevaskar@mednet.ucla.edu 


\section{Introduction}

The developing brain is highly dependent on energy metabolism that is fueled predominantly by glucose as the substrate $[1,2]$. During fetal life, the brain is a major utilizer of glucose that is primarily derived from the mother [3]. Its entry into the brain occurs by facilitative diffusion via the glucose transporter isoform 1 (GLUT1) expressed in the blood-brain barrier [4]. This is followed by transport via GLUT3 expressed in progenitors and neuronal cells [5]. While lack of GLUT1 resulted in developmental anomalies [6,7], lack of GLUT3 led to features consistent with autism spectrum disorders (ASDs) postnatally $[8,9]$, with both conditions causing microcephaly and electroencephalographic seizures [8-10]. In vitro studies have demonstrated a role for GLUT1 in vascular development of the brain [11], while GLUT3 serves glutamate-induced neuronal excitotoxic tolerance via $5^{\prime}$-adenosine monophosphate protein kinase activation [12]. Further, associations between increased GLUT3-mediated glucose transport and serotonin have been reported in N2A neuroblastoma cells and nonneuronal cells such as peripheral mononuclear and skeletal muscle cells $[13,14]$. In animal models of autism, disruption of the brain serotonin axis plays a major role in its pathophysiology [15, 16]. In addition, the oxytocin (OXT) axis in the brain has displayed a serotonin-counteracting effect, modulating immediate and long-term consequences [16-18]. Based on this cumulative information related to GLUT3 and serotonin and OXT axes, we questioned the early relationship between fetal brain GLUTs and the serotonin and OXT axes.

Serotonin (5-HT) modulates multiple physiological functions such as gastrointestinal motility, cardiovascular function, memory, and mood in adult humans. Among the multiple roles of serotonin, the most intriguing is its developmental role [19-21]. A role for serotonin in neurodevelopmental disorders, such as autism or anxiety/attention deficit hyperactivity disorder, led to the recognition of its importance during early-life development [19, 21-24]. During embryonic and postnatal development, serotonin modulates neuron cell division, migration and differentiation, axonal and dendritic elaboration, connectivity, and myelination [19]. Serotonin neurons in rodents appear at $\sim 10.5$ days of gestation $[19,25,26]$. Perturbed brain serotonin concentrations during critical windows of development have long-lasting effects on brain function, contributing toward the subsequent development of anxiety in the presence of high serotonin or depression when serotonin concentrations are low [20,
23]. The placenta has been identified as an important exogenous source of serotonin [26] in early pregnancy prior to the ability of the embryonic brain to produce de novo serotonin. During this early gestational period, the placenta plays a major role in maternal-fetal transfer of tryptophan, an essential amino acid that is converted to serotonin by the placental tryptophan hydroxylase (TPH) enzyme. Hence, the fetal brain serotonin axis is highly dependent on maternal diet at least during the early phase of pregnancy and continues to some extent during the latter part of pregnancy as well.

Serotonin transporter (SERT, or 5-HTT) is a major regulator of serotonin neurotransmission, and it has been implicated in the etiology of ASDs as well $[15,21]$. SERT is first expressed during prenatal murine brain development at E12, and by E18, it is found in all subcellular neuronal compartments $[21,27]$. During the course of embryonic development, SERT density peaks with advancing gestation, subsequently declining postnatally (P7) $[21,28]$. During critical stages of brain development, serotonin concentrations can influence the expression or function of key regulators of serotonin neurotransmission, including SERT [29]. SERT expression and function are influenced by a large and diverse array of intrinsic and extrinsic factors. Intrinsic factors include genetic variants, auto- and hetero-dimerization, cytokines, and hormones. Extrinsic factors such as diet, environmental stressors, and drugs can also have prominent effects on SERT expression and function. Less is known about how these factors might come into play during the prenatal critical phases of brain development $[21,29]$.

In contrast, OXT expression in the placenta increases with gestation [30-32] and is also expressed within the fetal hypothalamic paraventricular nucleus. OXT expression is detected as early as E14.5, following proliferation and migration of the hypothalamic neurons [33]. OXT neural connections extend into the hippocampus and cerebral cortex, where they interact with OXT receptors (OXTRs) $[34,35]$. OXTRs first appear at E18.5 and mediate the anti-stress response and sociability postnatally [33]. Studies in rodents have revealed OXT anti-seizure activity [36-40], with increasing inhibition [41], potentially curbing the imbalanced excitatory to inhibitory neurotransmission [41] characteristic of ASDs. Studies in OXTR (-/-) mice reveal a lack of cognitive flexibility as seen in ASDs [33]. These mice reveal postnatal feeding difficulties and lack of sociability subsequently in adult life [33]. These investigations, along with the purported interaction with serotonin, have provided a potential for therapeutic possibilities in ASDs [16-18].
Ye/Shin/Baldauf/Ganguly/Ghosh/ Devaskar 
Maternal dietary perturbations affecting early-life neurodevelopment have led to altered adult neurobehaviors. In particular, a hypercaloric cafeteria or Western diet has led to either anxiety or depression associated with increased or decreased brain serotonin axis in primates and rodents, respectively $[42,43]$. On the other hand, maternal protein-restricted diet led to a reduction in brain serotonin receptors [44]. Maternal caloric restriction was associated with adult-onset anxiety in female rodents [45]. In lieu of dietary modifications, environmental exposures that modify maternal glucose and/ or fat metabolism [46, 47] also have the propensity of affecting neurodevelopment postnatally. One such prenatal exposure is to traffic-related air pollution (AP) gauged by living close to traffic-heavy highways in humans or instillation of mixtures of air pollutants in rodents mimicking that generated by heavy traffic [48-50]. Changes in glucose and fat metabolism with associated emergence of ASDs [48-50] have been reported. However, in all these studies, while early perturbations in diet or air pollutant exposures were associated with the ultimate behavioral changes during adult life, there is not much focus on fetal brain changes and its immediate impact on neurodevelopment. To this end, we have previously developed maternal dietary modified murine models. Maternal caloric restriction introduced beginning at E10 through gestation led to significant changes in neurodevelopment [51] associated with long-term emergence of anxiety [45]. On the other hand, a maternal high-fat (HF) dietary model previously reported by us led to glucose and fat metabolic changes in the mother and placenta [52]. Others have employed SRM1649 (a mixture of traffic-related air pollutants consisting of organic and inorganic substances with a $\mathrm{PM}_{2.5-10}$ range) [53] in vitro which we combined with an instillation in vivo model [54], producing gestational exposure to traffic-related air pollutants.

Given that alterations in maternal diet, whether composed of calorie restriction or exposure to a HF diet, and traffic-related air pollutants lead to long-term changes in neurobehavior, we questioned the role of maternal exposures, both dietary and traffic-related AP, upon fetal brain expression of key molecules essential for the normal development of neural axes and function. We hypothesized that prenatal exposures to calorie restriction, HF-containing diet, or AP will perturb late gestation embryonic brain GLUTs, which in turn will prove detrimental to the serotonin-SERT axis, with the OXT-OXTR axis potentially counterbalancing this effect. We tested this hypothesis in our established pregnant mouse models.

Brain Serotonin, SERT, and OXTR during

Development

\section{Materials and Methods}

\section{Animal Models}

Wild-type C57/BL6 female mice purchased from the UCLA Division of Laboratory Animal Medicine (obtained from The Jackson Lab, Bar Harbor, ME, USA) were housed in 12-h light and 12-h dark cycles, and care or treatment was provided according to the UCLA Animal Research Committee-approved protocol in accordance with the guidelines set by the National Institutes of Health regarding the Care and Use of Laboratory Animals.

1. Dietary modifications: we employed 3 different animal groups for our studies: control group (CON) on regular chow diet, maternal calorie restriction (intrauterine growth restriction [IUGR]), and a high fat (HF) hypercaloric group (Fig. 1).

2. Traffic-related AP: 2 groups were engaged, where 1 group received nasal instillation of SRM1649 suspension (obtained from the National Institute of Standards and Technology

[Gaithersburg, MD, USA]) and the other group saline.

Wild-type C57/BL6 female mice (2 or 3 months old) in all groups were mated with male counterparts. The presence of a vaginal plug was designated as gestational day 1 .

Maternal Caloric Restriction (IUGR) Studies

On gestational day 10 , pregnant mice were arbitrarily assigned to the CON with ad libitum access to a standard rodent chow diet (TD. 06414, Harlan Teklad Laboratories, Indianapolis, IN, USA; composition: carbohydrate $63.9 \%$, fat $4.5 \%$, and protein $14.5 \%$ ) and water. IUGR was produced by maternal dietary restriction ( $~ 50 \%$ calories from gestational day 10 to day 19 , calculated based on daily chow intake/day by ad lib-fed pregnant mice considered to be $100 \%$ ) [55] (Fig. 1).

\section{Hypercaloric HF Studies}

Wild-type C57/BL6 female mice were housed with ad libitum access to a standard rodent chow diet and water till 4 weeks of age. During the fifth week of life, female mice were given a HF diet (TD 88137; Harlan Teklad Laboratories, Indianapolis, IN composition: carbohydrate $45 \%$, fat $42 \%$ and protein $13 \%$ ). At 12 weeks of life, the HF-fed females were mated with regular chow fed male counterparts. After confirming the presence of a vaginal plug, pregnant females were given HF diet until E19 [52] (Fig. 1).

Traffic-Related AP Exposure Studies

Female mice from gestational day 1 to 18 received daily either SRM1649 suspended in $20 \mu \mathrm{L}$ of sterile saline (AP group) or an equal volume of sterile saline (CON) intranasally (divided between the 2 nares) under light restrain. SRM1649 $(15 \mu \mathrm{g} / \mu \mathrm{L})$ (obtained from the National Institute of Standards and Technology [Gaithersburg, MD, USA]) was suspended in sterile saline and sonicated for $15 \mathrm{~min}$ to ensure uniform suspension of dissoluble PAHs, PCBs, and inorganic constituents with a heterogeneous PM size reduced to a range between $\sim \mathrm{PM}_{2.5}$ and $\sim \mathrm{PM}_{10}$ (Fig. 1), thereby simulating traffic-related air pollutants.

All the experimental groups on gestational day 19 underwent hysterotomy under inhalational isoflurane (4\% for induction, and $1.25-1.5 \%$ for maintenance). Upon delivery of the embryos, they were weighed. Heads were separately weighed, brains collected after craniotomy, then snap-frozen immediately in liquid nitrogen, and stored in $-80^{\circ} \mathrm{C}$ until further analyses. All embryos from a single pregnancy constituted $n=1$.

Dev Neurosci 2021;43:27-42 


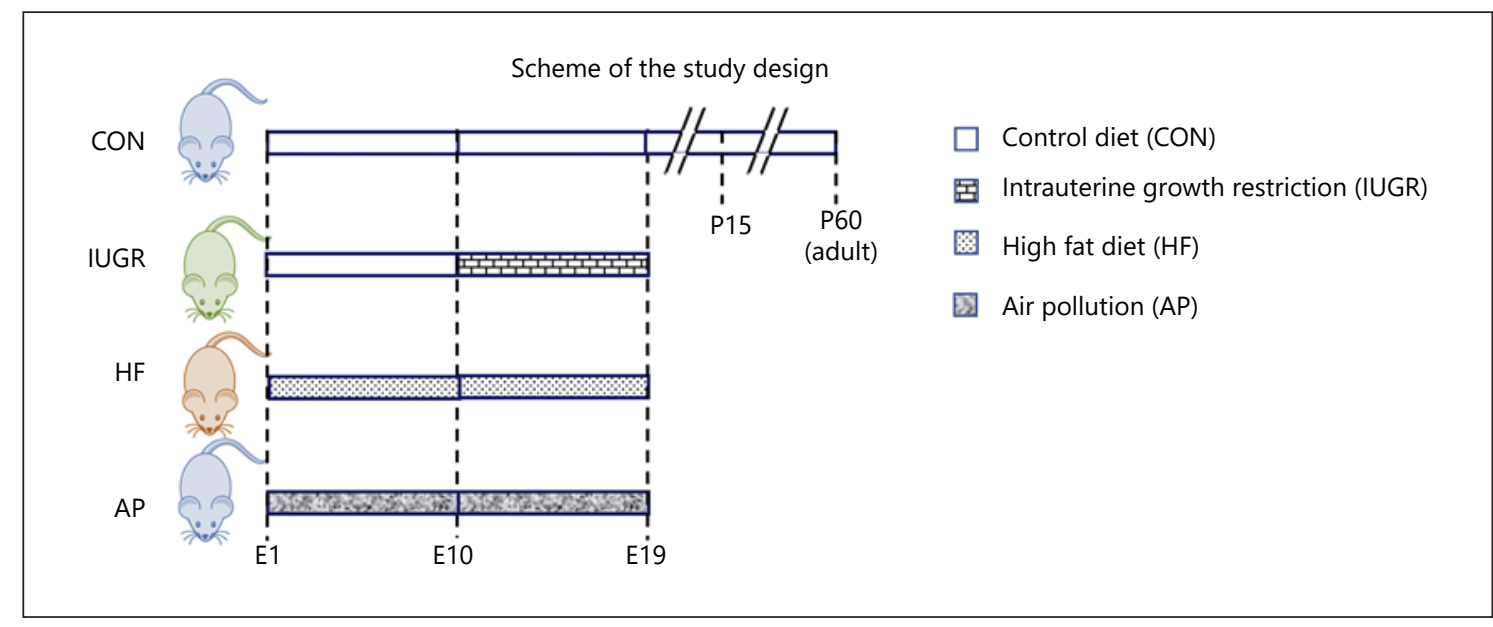

Fig. 1. Experimental design: the scheme demonstrates the experimental design: (1) compared to CON mothers reared on regular chow diet, (2) IUGR group mothers received reduced regular chow diet from gestational day 10 to 19. (3) In the HF diet group, mothers received HF diet for 8 weeks prior to pregnancy plus during gestation days 1-19. (4) AP group mothers received SRM1649 (AP) intranasally while being reared on a regular chow diet from $\mathrm{E} 1$ to $\mathrm{E} 18$, while the respective $\mathrm{CON}$ received intranasal saline. IUGR, intrauterine growth restriction; $\mathrm{HF}$, high fat; AP, air pollution; CON, control group.

\section{Antibodies}

Mouse anti-SERT (Frontier, Hokkaido, Japan), rabbit antisynaptophysin (Millipore, Temecula, CA, USA), rabbit antiGLUT1 (Abcam, Burlingame, CA, USA), rabbit anti-GLUT3 (gift from Dr. Takata in Japan), rabbit anti-OXTR (Thermo Fisher Scientific, Waltham, MA, USA), mouse anti-vinculin, and anti- $\beta$ actin (Sigma Chemical Co., St. Louis, MO, USA) antibodies were employed in our studies (Table 1).

\section{Immunohistochemistry}

Mouse brains were collected following craniotomy and embedded in O.T.C. compound (Tissue-Tek, Torrance, CA, USA). Tissue samples were snap-frozen in liquid nitrogen and stored in $-80^{\circ} \mathrm{C}$. Frozen serial coronal whole-brain sections $(10 \mu \mathrm{m})$ were obtained using a cryostat (Leica Microsystems, CM1850, Nussloch, Germany), and these sections were mounted onto slides. Sections were fixed in $100 \%$ ethanol at $-20^{\circ} \mathrm{C}$ for $20 \mathrm{~min}$ followed by washing 3 times with PBS for $5 \mathrm{~min}$, each.

The slides containing sections were first incubated for $1 \mathrm{~h}$ with $5 \%$ normal donkey serum containing $0.2 \%$ Triton X-100 and $1 \%$ gelatin, followed by incubation at room temperature for $1 \mathrm{~h}$ with different primary antibodies: (mouse anti-SERT, 1:500 dilution [Frontier, Hokkaido, Japan]; rabbit anti-synaptophysin, 1:500 [Millipore, Temecula, CA, USA, USA]; rabbit anti-OXTR, 1:200 [Thermo Fisher Scientific, Waltham, MA, USA]; and rabbit antiGLUT3 [Dr. Takata in Japan]). Following washing with PBS 3 times for $5 \mathrm{~min}$ each, corresponding secondary antibodies carrying the fluorescence detection tags (Alexa Fluor 488 or Alexa Fluor 594 [Jackson Immuno-Research Laboratories, West Grove, PA, USA]) were incubated at room temperature for $1 \mathrm{~h}$ at 1:500 dilution. 4',6-diamidino-2-phenylindole (1:1,000 dilution) was used to stain the cellular nuclei. Tissue sections were visualized using a Nikon E-600 microscope (Nikon, Melville, NY, USA) equipped with a cooled, charge-coupled device camera (CoolSNAP HQ Mono- chrome; Roper Scientific, Tucson, AZ, USA), and the images captured by MetaMorph software (www.moleculardevices.com, RRID: SCR_002368) [9].

\section{ELISA: Brain Serotonin}

Brain serotonin concentrations were measured in duplicates within supernatants (50 $\mu \mathrm{g}$ protein measured by the Bio-Rad assay) of brain tissue homogenates by an ELISA kit (Serotonin High Sensitive ELISA, Eagle Biosciences, Nashua, NH, USA) that has previously been validated [56]. The range of measurements is from 0 to $100 \mathrm{pg} / 50 \mu \mathrm{g}$. Sensitivity is $0.39 \mathrm{pg} / \mathrm{sample}$, and the specificity is $\sim 100 \%, 0.22 \%$ for tryptamine, $0.025 \%$ for 5 -methoxytryptamine, $0.0021 \%$ for 5 -hydroxytryptophan, $<0.001$ for melatonin and 5-HIAA, and $<0.0001$ for L-tryptophan. The intra-assay coefficient of variation ranged from 6.6 to $8.7 \%$.

\section{Western Blot Analyses}

Cerebral tissues were homogenized and sonicated in RIPA buffer (20 mM Tris- $\mathrm{HCl}$ ( $\mathrm{pH} 7.5), 150 \mathrm{mM} \mathrm{NaCl}, 1 \mathrm{mM} \mathrm{Na}{ }_{2}$ EDTA $1 \mathrm{~mm}$ EGTA 1\% NP-40, 1\% sodium deoxycholate, $2.5 \mathrm{~mm}$ sodium pyrophosphate, $1 \mathrm{~mm} \beta$-glycerophosphate, $1 \mathrm{mM} \mathrm{Na}_{3} \mathrm{VO}_{4} 1 \mu \mathrm{g} / \mathrm{mL}$ leupeptin (Pierce, Waltham, WA, USA)) with protease inhibitors (Thermo Scientific, Canoga Park, CA, USA) including $2 \mathrm{mM}$ PMSF, as previously subscribed $[9,51]$. The resulting homogenate was centrifuged at $10,000 \mathrm{~g}$ at $4^{\circ} \mathrm{C}$ for $10 \mathrm{~min}$, and the protein content was measured by the Bio-Rad protein assay (Bio-Rad Laboratories, Irvine, CA, USA) and subjected to Western blot analysis. In brief, homogenates ( $30 \mu \mathrm{g}$ of protein) were subjected to sodium dodecyl sulfate polyacrylamide gel electrophoresis and the separated proteins transferred to nitrocellulose membrane filters (BioRad, Hercules, CA, USA). The membranes were washed with PBST 3 times for 5 min each and blocked in 3\% bovine serum albumin for $1 \mathrm{~h}$, followed by overnight incubation at $4^{\circ} \mathrm{C}$ with the specific primary antibodies, mouse anti-SERT antibody (1:500 di-
30

Dev Neurosci 2021:43:27-42

DOI: $10.1159 / 000514709$
Ye/Shin/Baldauf/Ganguly/Ghosh/ Devaskar 
Table 1. Details of antibodies employed in the study

\begin{tabular}{|c|c|c|c|}
\hline Antibody & Manufacturer details & Description & Concentration/data \\
\hline GLUT1 & $\begin{array}{l}\text { Abcam } \\
\text { Cat no: ab652 } \\
\text { RRID: AB_305540 } \\
\text { Species: rabbit } \\
\text { Polyclonal }\end{array}$ & $\begin{array}{l}\text { Synthetic peptide conjugated to KLH, } \\
\text { corresponding to amino acids } 478-492 \text { of human } \\
\text { GLUT1 }\end{array}$ & $\begin{array}{l}\text { Rabbit/1:1,000/Western } \\
\text { blot; IHC }\end{array}$ \\
\hline SERT & $\begin{array}{l}\text { Frontier Institute co. Ltd. } \\
\text { Cat no: HTT-Rb-AF560 } \\
\text { RRID: AB_2571775 } \\
\text { Species: Rabbit } \\
\text { Polyclonal }\end{array}$ & Antigen: mouse HTT, 1-77 aa & $\begin{array}{l}\text { Rabbit/1:500/Western } \\
\text { blot, IHC }\end{array}$ \\
\hline OXTR & $\begin{array}{l}\text { Thermo Fisher } \\
\text { Cat no: PA5-77764 } \\
\text { RRID: AB_2736284 } \\
\text { Species: rabbit } \\
\text { Polyclonal }\end{array}$ & $\begin{array}{l}\text { Synthetic peptide conjugated to KLH derived from } \\
\text { within residues } 346-358 \text { of rat OXTR }\end{array}$ & $\begin{array}{l}\text { Rabbit/1:200/Western } \\
\text { blot }\end{array}$ \\
\hline$\beta$-Actin & $\begin{array}{l}\text { Cell signaling Technology, } \\
\text { Cat no: } 8457 \\
\text { RRID: AB_10950489 } \\
\text { Species: Rabbit } \\
\text { Polyclonal }\end{array}$ & $\begin{array}{l}\text { A synthetic peptide corresponding to residues near } \\
\text { the amino terminus of human } \beta \text {-actin protein }\end{array}$ & $\begin{array}{l}\text { Rabbit/1:20,000/Western } \\
\text { blot }\end{array}$ \\
\hline
\end{tabular}

The source, antigen against which antibody was generated, and the host and dilution of antibodies employed in the study are presented. SERT, serotonin transporter; OXTR, oxytocin receptor; GLUT, glucose transporter.

lution), rabbit anti-GLUT1 (1/1,000 dilution), anti-GLUT3 (1/1,000 dilution), or anti-OXTR (1/200 dilution). Membranes were subsequently washed in PBST 6 times for 5 min each and incubated at room temperature over $45 \mathrm{~min}$ with the appropriate secondary horseradish peroxidase-conjugated antibody (Pierce, Waltham, WA, USA). The proteins were visualized in a ChemiDoc Imaging System (BioRad, Hercules, CA, USA) or Typhoon Scanner (GE Healthcare, Pasadena, CA, USA) by blotting with the enhanced chemiluminescence plus detection kit (GE Healthcare BioSciences Corp., Piscataway, NJ, USA) following horseradish peroxidase-labeled anti-rabbit IgG for anti-GLUT1, anti-GLUT3, anti- $\beta$-actin (1:20,000 dilution), and anti-OXTR or anti-mouse
IgG for anti-vinculin (1:60,000 dilution) (Sigma, St. Louis, MO, USA). Each protein was quantified by using Image Lab software (Bio-Rad, Hercules, CA, USA) or ImageQuant software (GE Healthcare, Pasadena, CA, USA), normalized to either vinculin or $\beta$-actin as an internal control (each one chosen based on the molecular weight of the primary protein, to prevent overlap in visualization/quantification of the primary protein vs. the respective internal control) and expressed as percent of respective CON values.

Sex as a Biological Variable

Intersex difference was explored between E19 CON and IUGR as well as at developmental time points E19, P15, and adult. A total 


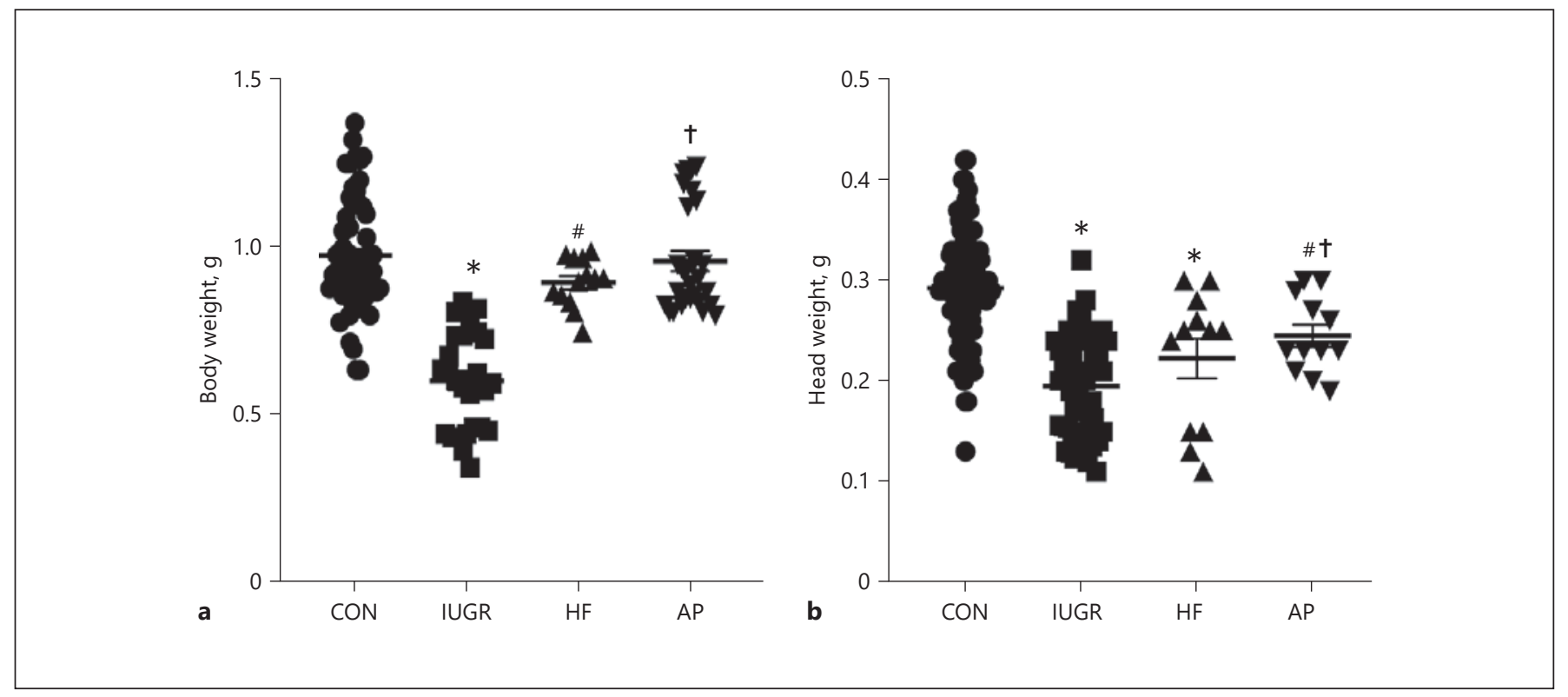

Fig. 2. Fetal (E19) body weights (a) and head weights (b). Fetal (E19) body (a) and head (b) weights are depicted in all 4 experimental groups. Body weights (a), one-way ANOVA, F-statistic: 3, $125=39.18, p<0.0001$, by Sidak's multiple comparisons post hoc test, ${ }^{*} p<0.0001$ versus CON, ${ }^{*} p<0.0001$ or ${ }^{\dagger} p<0.0001$ versus IUGR; $n=61$ in CON, $n=27$ in IUGR, $n=13$ in HF, and $n=28$ in AP. Head weights (b), one-way ANOVA, F-statistic: 3, $165=$
40.06, $p<0.0001$, by Sidak's multiple comparisons post hoc test, ${ }^{*} p=0.0001$ or $^{\#} p=0.0217$ versus CON, ${ }^{\dagger} p=0.0213$ versus IUGR; $n=92$ in CON, $n=53$ in IUGR, $n=12$ in HF, and $n=12$ in AP. Data are shown as means \pm standard error of the mean. IUGR, intrauterine growth restriction; $\mathrm{HF}$, high fat; $\mathrm{AP}$, air pollution; $\mathrm{CON}$, control group.
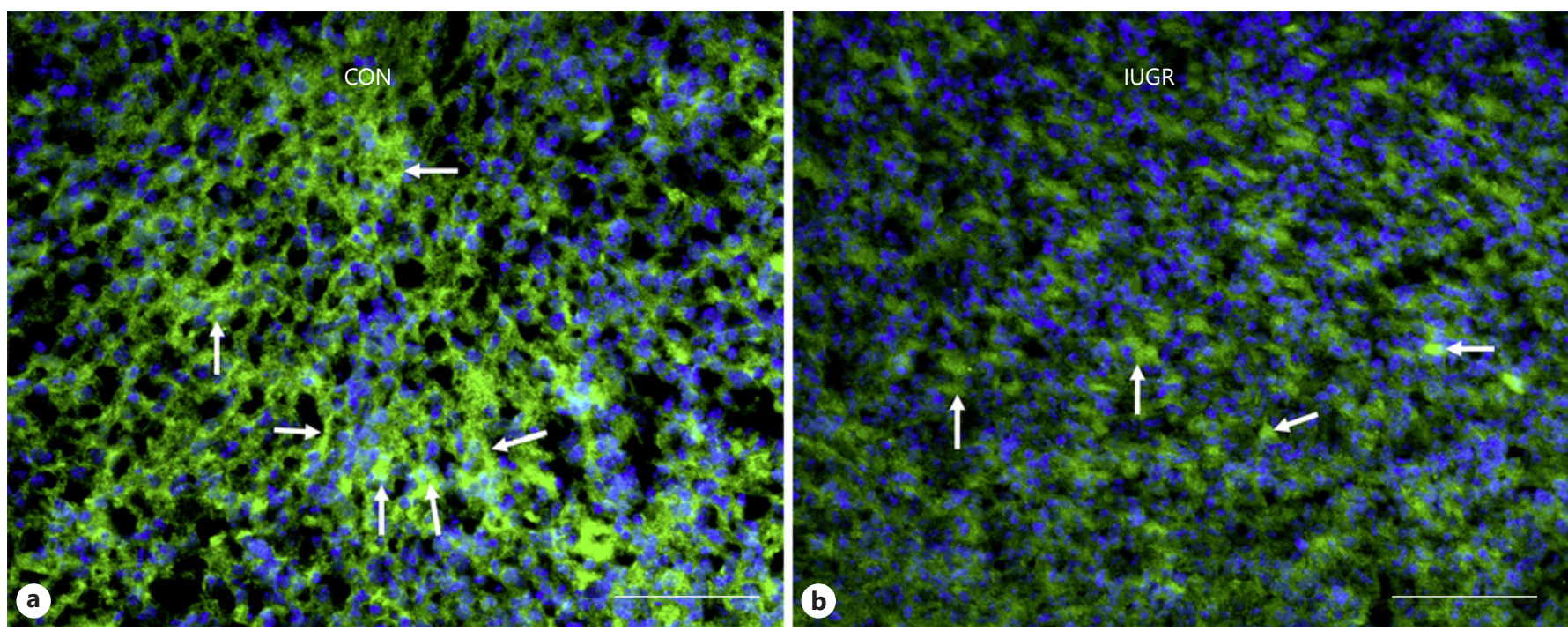

Fig. 3. Immunofluorescence localization of GLUT3. Alexa 488, green in neural membranes, shown by arrows in the E19 fetal brain (cortex) of CON (a) and IUGR (b) groups, with DAPI nuclear stain (blue). The expression of GLUT3 protein was decreased in the cortex of IUGR compared to CON. Scale bars $=100 \mu \mathrm{m}$. IUGR, intrauterine growth restriction; CON, control group; GLUT, glucose transporter; DAPI, 4',6-diamidino-2-phenylindole. 


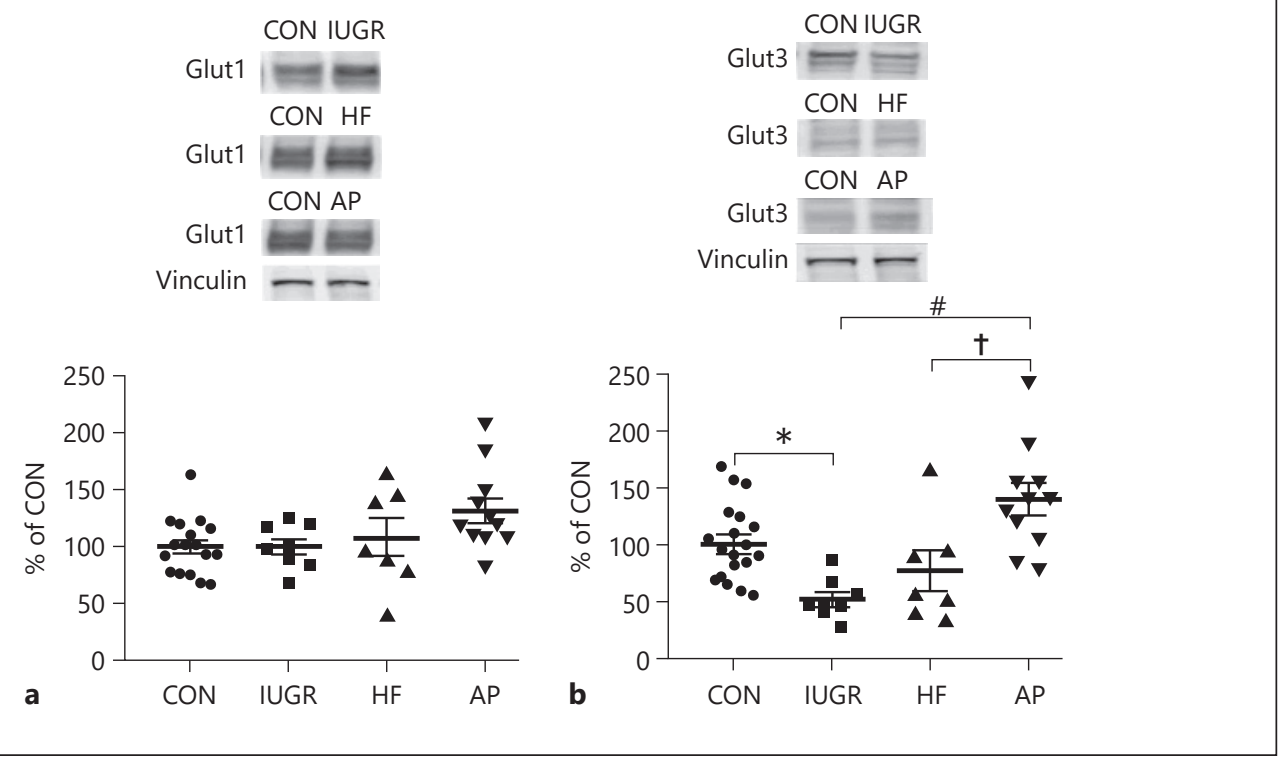

Fig. 4. Western blot analysis of GLUT1 (a) and GLUT3 (b). Top panels show representative blots with GLUT1 and GLUT3 shown above and vinculin as the internal loading control shown below. GLUT1 and GLUT3 protein concentrations quantified by Western Blot analysis in IUGR, HF, and AP versus CON. a GLUT1 expression in the CON, IUGR, HF, and AP groups. There are no significant differences between groups (one-way ANOVA, F-statistic: 3, $39=2.651, p=0.0621, n=17$ for CON, $n=8$ for IUGR, $n=7$ for $\mathrm{HF}$, and $n=11$ for AP). b However, GLUT3 concentrations were significantly decreased to $48 \%$ in IUGR when compared to CON.
In addition, in the AP group, brain GLUT3 concentrations were 2.7-fold increased or 1.8-fold increased when compared to IUGR or $\mathrm{HF}$, respectively (b) (one-way ANOVA, F-statistic: 3, $39=$ 8.981, $p=0.0001, n=17$ for CON, $n=8$ for IUGR, $n=7$ for HF, and $n=11$ for AP; Sidak's multiple comparisons post hoc test, ${ }^{*} p=0.0318$, CON vs. IUGR; ${ }^{*} p<0.0001$, IUGR vs. AP; ${ }^{\dagger} p=0.009$, HF vs. AP). Data are shown as means \pm standard error of the mean. IUGR, intrauterine growth restriction; HF, high fat; AP, air pollution; CON, control group; GLUT, glucose transporter.

of 120 male and 120 female mice were included in the study. The remaining data analyses, again denoted in the results and figure legends, were not subanalyzed as animals were not sexed prior to obtaining samples.

\section{Genotyping for Sex Determination}

Genetic sex determination of E19 embryos was performed, as previously described [51]. In brief, for genetic sex determination, extracted tail DNA fragments of either the X-chromosomal Xlr gene (X-linked lymphocyte-regulated complex) or the Y-chromosomal Sly gene (Sycp3-like Y-linked) were amplified using genespecific PCR primers [51, 57]. The PCR conditions consisted of denaturation at $95^{\circ} \mathrm{C}$ for $2 \mathrm{~min}$, followed by 35 cycles of denaturation at $95^{\circ} \mathrm{C}$ for $30 \mathrm{~s}$, annealing at $58^{\circ} \mathrm{C}$ for $30 \mathrm{~s}$, and extension at $72^{\circ} \mathrm{C}$ for $30 \mathrm{~s}$. Finally, extension at $72^{\circ} \mathrm{C}$ for $5 \mathrm{~min}$ was done. Sex at $\mathrm{P} 15$ and adult stages was determined by visualization of the external genitalia.

\section{Data Analyses}

Data are expressed as mean \pm standard error of the mean. Sample size was predetermined by conducting a power analysis employing StatMate software at a power of $80 \%$ and a $p$ value of 0.05 . ANOVA models were used to compare various treatment groups and statistical significance established by Prism (7th edition) soft- 


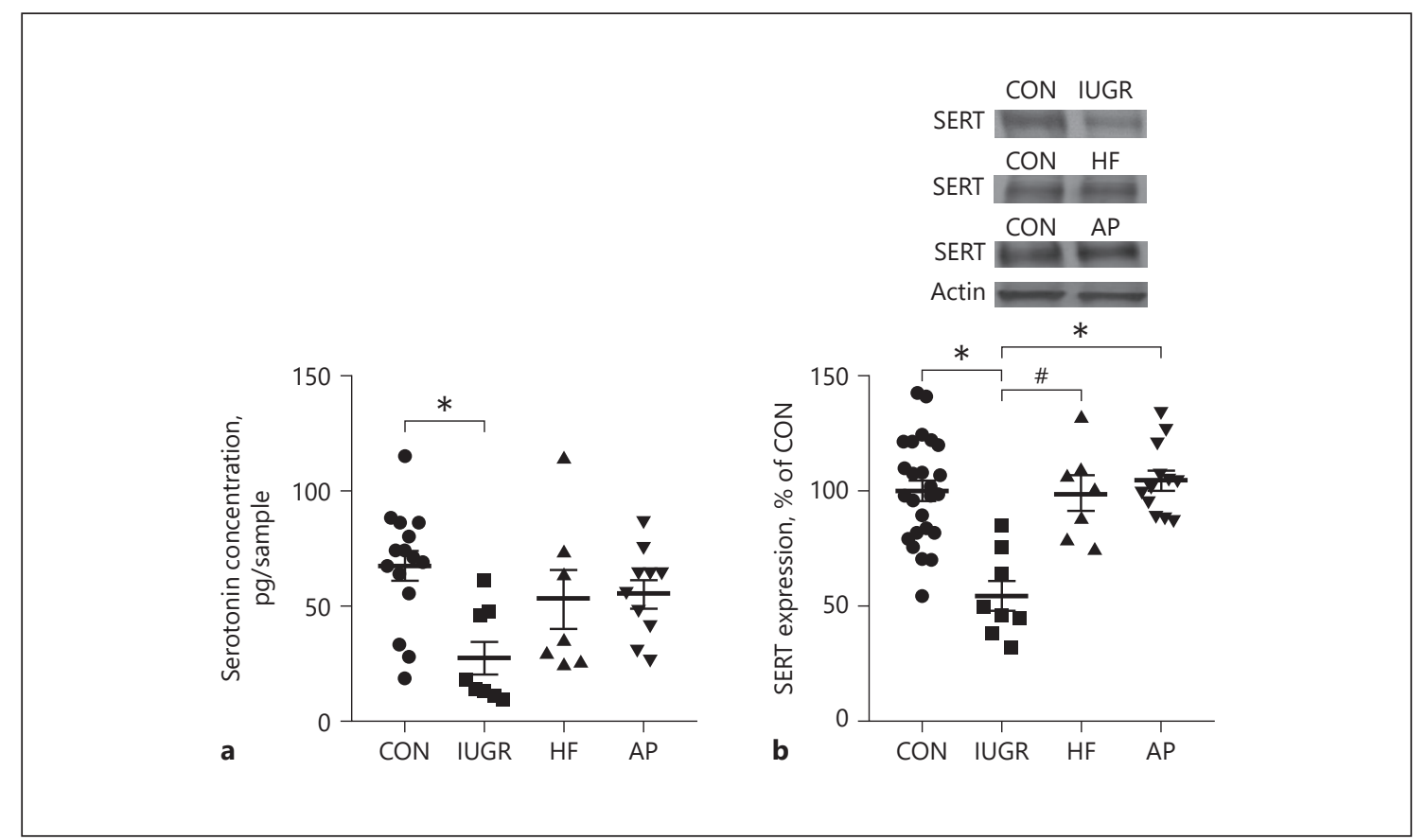

Fig. 6. Quantification of serotonin and SERT: the graphs demonstrate E19 brain serotonin concentrations quantified by ELISA (a) and SERT concentrations quantified by Western blot analysis (b), in IUGR, HF, and AP versus CON. Serotonin: Fetal murine brain serotonin concentrations (a) decreased in the IUGR but not in HF or AP groups when compared to CON. (one-way ANOVA, F-statistic: $3,36=4.605, p=0.0079, n=15$ for CON, $n=7$ for HF, $n=$ 8 for IUGR, and $n=10$ for AP; Tukey's post hoc test demonstrates ${ }^{*} p=0.0037$ in IUGR vs. CON). When comparing IUGR to HF and AP groups, no significant differences emerged, although the AP group trended higher than IUGR $(p=0.0974)$. SERT protein: $(\mathbf{b})$

ware (www.graphpad.com, RRID:SCR_002798). Intergroup differences were determined post hoc by either Tukey's or Sidak's multiple comparison test. When only 2 experimental groups were compared, Student's unpaired $t$ test was employed. Significance was assigned when the $p$ value $<0.05$.

\section{Results}

\section{Fetal Mouse Body and Head Weights}

Examination of fetal (E19) body weights revealed a reduction only in the IUGR group $(p<0.0001)$ compared to the other groups (Fig. 2a). Similarly, a decrease in head weight was also seen in the IUGR group ( $p=$ 0.0001 ) when compared to CON (Fig. 2b). Additionally, a reduction in head weights emerged in the $\mathrm{HF}(p=$ $0.001)$ and $\operatorname{AP}(p=0.0217)$ groups when compared to $\mathrm{CON}$.
Top panels display representative blots of SERT shown above and $\beta$-actin as the internal loading control shown below. The bottom graphs depict quantification of Western blots demonstrating decreased SERT in the IUGR group when compared to age-matched $\mathrm{CON}\left({ }^{*} p<0.0001\right), \mathrm{HF}\left({ }^{*} p=0.0005\right)$ and AP $\left({ }^{*} p<0.0001\right)$ groups (one-way ANOVA, F-statistic: 3, $48=12.41, p<0.0001, n=25$ for CON, $n=7$ for HF, $n=8$ for IUGR, and $n=12$ for AP; Tukey's post hoc test, ${ }^{*} p<0.0001$ vs. CON or AP; ${ }^{*} p=0.0005$ vs. HF). Data are shown as means \pm standard error of the mean. SERT, serotonin transporter; IUGR, intrauterine growth restriction; HF, high fat; $\mathrm{AP}$, air pollution; $\mathrm{CON}$, control group.

GLUT1 and GLUT3 Protein in E19 Fetal CON, IUGR, $H F$, and AP Mouse Brain

Immunofluorescence localization of GLUT3 with Alexa 488 is shown in neural membranes within E19 CON (Fig. 3a) and IUGR (Fig. 3b) brain sections. The intensity of GLUT3 immunostaining was decreased in the cortex of IUGR compared to CON (Fig. 3). In addition, by Western blot analysis of E19 fetal CON, IUGR, HF, and AP brains (Fig. 4), while there was no difference among the CON, IUGR, HF, and AP GLUT1 concentrations (Fig. 4a) (oneway ANOVA, F-statistic: 3, $39=2.651, p=0.0621, n=17$ for CON, $n=8$ for IUGR, $n=7$ for HF, and $n=11$ for AP), GLUT3 concentrations were significantly decreased to $48 \%$ in IUGR when compared to CON at E19 (Fig. 4b). The pattern of reduction was similar in male and female animals (see online suppl. Fig. 1; for all online suppl. material, see www.karger.com/doi/10.1159/000514709). However, in the AP group, brain GLUT3 concentrations
Dev Neurosci 2021;43:27-42 DOI: $10.1159 / 000514709$
Ye/Shin/Baldauf/Ganguly/Ghosh/ Devaskar 
Fig. 7. Immunofluorescence localization of OXTR: Alexa 488, green in the hypothalamus $(\mathbf{a}, \mathbf{b})$ and hippocampus $(\mathbf{c}, \mathbf{d})$ of postnatal day 15 brain (cortex) with DAPI nuclear stain (a, c, blue). The OXTR protein was expressed in neural membranes (arrows). Scale bars $=100 \mu \mathrm{m}$. OXTR, oxytocin receptor; DAPI, 4',6-diamidino-2-phenylindole.
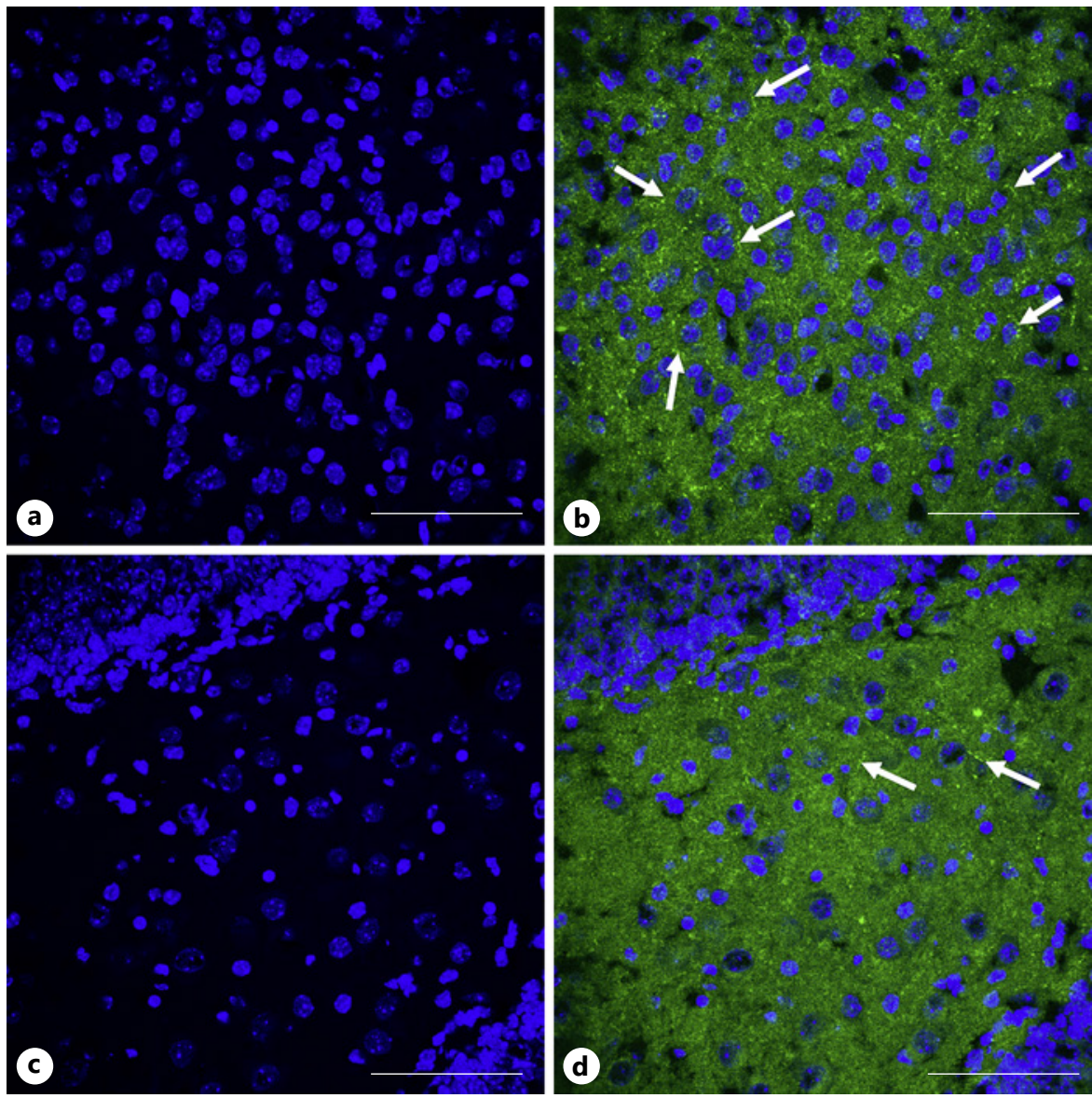

were 2.7 fold-increased or 1.8 fold-increased when compared to IUGR or HF, respectively (Fig. 4b) (one-way ANOVA, F-statistic: 3, $39=8.981, p=0.0001, n=17$ for CON, $n=8$ for IUGR, $n=7$ for HF, and $n=11$ for AP; Sidak's multiple comparisons post hoc test, ${ }^{*} p=0.0318$, CON vs. IUGR; ${ }^{*} p<0.0001$, IUGR vs. AP; ${ }^{\dagger} p=0.009$, HF vs. AP).

\section{Validation of the SERT Antibody Using}

\section{Immunohistochemistry}

The specificity of the mouse and rat SERT antibodies was validated in adult mouse brain frontal cortical sections by immunohistochemistry, as shown in Figure 5 . SERT was reported to be located in presynaptic 5-HT nerve terminals and 5-HT cell bodies [21]. No co-localization of SERT with synaptophysin, which is a marker of presynaptic neuronal axons, was seen (Fig. 5), supporting the expression of SERT on neuronal bodies that lack synaptophysin immunostaining.

Brain Serotonin, SERT, and OXTR during Development
Serotonin and SERT Protein in E19 Fetal Mouse Brain Serotonin concentrations decreased by $60 \%$ (one-way ANOVA, F-statistic: $3,36=4.605 p=0.0079$ Tukey's post hoc test ${ }^{*} p=0.0037$ ) (Fig. 6a) and SERT protein expression (Fig. 6b) decreased by $46 \%$ (one-way ANOVA, Fstatistic: $3,48=12.41, p<0.0001$. Tukey's test $\left.{ }^{*} p<0.0001\right)$ in response to maternal calorie restriction (IUGR) $(n=8)$ when compared to age-matched CON $(n=15)$. In contrast, no statistically significant change was observed in fetal brain (E19) serotonin and SERT concentrations in response to maternal HF dietary exposure $(n=7)$ versus CON $(n=15)$, despite a decreasing trend observed in brain serotonin concentrations in the HF group versus CON (Fig. 6a, b). Similarly, no difference in serotonin and SERT concentrations was evident following maternal exposure to simulated AP (Fig. 6a, b).

\section{OXTR in Mouse Brain}

We initially employed immunostaining to determine the specificity of the OXTR antibody (Fig. 7). Employing 
Fig. 8. Quantification of OXTR: ontogeny studies: Examination of OXTR at E19, PN 15 , and adult (2 months old) mouse cortices. Western blot analysis showing representative blots in insets that depict cortical OXTR $(\sim 43 \mathrm{kD})$ (top panels) with vinculin (vin; bottom panels, internal loading control), and quantification expressed as percent of the E19 value (a-c) or of the E19 CON value (d), depicted in graphs. Male mice (a), female mice (b), and male and female mice combined (c) are demonstrated. In males (a), the expression of OXTR significantly increased in PN15 and adult compared to E19 (one-way ANOVA, Fstatistic: $2,9=10.64, p=0.0043, n=4$ each group; Sidak's post hoc test, ${ }^{*} p=0.05$ vs. E19, ${ }^{\#} p=0.0041$ vs. E19). In female mice (b), there was no difference among the 3 groups of females (one-way ANOVA, $F$ statistic: $2,9=2.877, p=0.1081, n=4$ each group; Sidak's post hoc test; P15 vs. E19, $p=0.4027$ : adult vs. E19, $p=0.1219$ : adult vs. P15, $p=0.8170)$. However, in the combined groups of male and female mice (c), the amount of OXTR significantly increased in adult compared to E19 (one-way ANOVA, F 2, $21=7.145, p=0.0043, n=8$ each group; Sidak's post hoc test, P15 vs. E19, $p=0.09$ : adult vs. E19, ${ }^{*} p=0.0035$ : adult vs. P15, $p=0.4078$ ). In the E19 brain OXTR concentrations of CON, IUGR, HF, and AP groups (d), there was no significant difference observed, despite a trend toward a $16 \%$ decrease in the AP group when compared to CON (one-way ANOVA, F-statistic: $3,39=0.7615, p=0.5225, n=17$ for CON, $n=8$ for IUGR, $n=7$ for HF, and $n=11$ for AP). Data are shown as means \pm standard error of the mean. OXTR, oxytocin receptor; IUGR, intrauterine growth restriction; HF, high fat; $\mathrm{AP}$, air pollution; $\mathrm{CON}$, control group; $\mathrm{PN}$, postnatal.

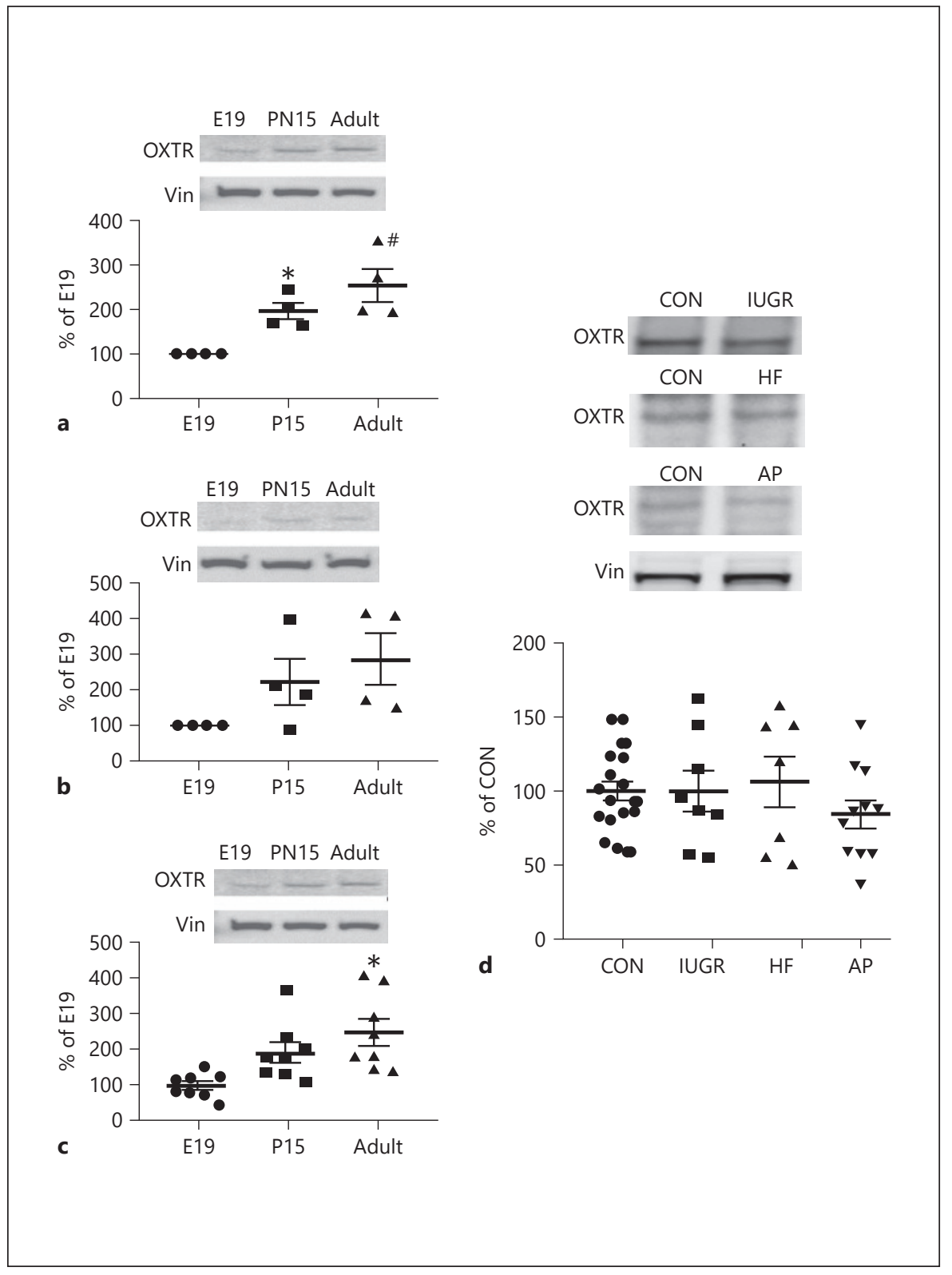

postnatal brain sections, we noted the presence of OXTR in the cortex (Fig. 7a, b) and hippocampus (Fig. 7c, d). Following these analyses, we next confirmed the presence of OXTR in the mouse cortex that is enriched in neuronal GLUT3. We initially analyzed the temporal expression of OXTR at different developmental stages, E19, P15, and adults in both male (Fig. 8a) and female (Fig. 8b) mice by Western blot analysis (Fig. 8a-c). In male animals, the expression of OXTR significantly increased at P15 and adult stages compared to E19 (one-way ANOVA, F-statistic: $2,9=10.64, p=0.0043, n=4$ each group; Sidak's multiple comparisons post hoc test, ${ }^{*} p=0.05$ vs. E19, ${ }^{\#} p=0.0041 \mathrm{vs}$. E19). In contrast, no difference among the 3 developmental stages in female mice was seen. When male and female mice were combined (Fig. 8c), OXTR amounts significantly increased at the adult stage when compared to E19 (one-way ANOVA, F-statistic: 2, $21=$ $7.145, p=0.0043, n=8$ each group; Sidak's multiple comparisons post hoc test, ${ }^{*} p=0.0035$ vs. E19).

Since we had observed a reduction in E19 brain GLUT3 concentrations in IUGR compared to CON (Fig. 3, 4), we next investigated brain OXTR concentrations in CON, 
IUGR, HF, and AP groups (Fig. 8d). There was no significant difference observed despite a trend toward a $16 \%$ decrease in the AP group when compared to CON (oneway ANOVA, F-statistic: $3,39=0.7615, p=0.5225, n=$ 17 for CON, $n=8$ for IUGR, $n=7$ for HF, and $n=11$ for $\mathrm{AP})$. In addition, a trend toward a decrease was also evident in the IUGR male group $\left(t_{6}=1.51, p=0.1818, n=4\right.$ each) compared to the sex-matched CON (online suppl. Fig. 2A). No difference in the female IUGR group (online suppl. Fig. 2B) or the combined male and female IUGR group (online suppl. Fig. 2C) versus the respective CON was observed.

\section{Discussion}

We have demonstrated that maternal caloric restriction induced IUGR reduced late gestation fetal brain GLUT3 expression, while not significantly affecting GLUT1. This decrease of $\sim 50 \%$ reflects prior studies of the classical glut3 heterozygous (glut3+/-) embryonic null mice [58] where genetic modification achieved the same end result as IUGR. The glut3+/- embryos went on to subsequently develop neurobehavioral changes [8]. These neurobehavioral changes consisted of abnormal spatial learning, working memory and abnormal cognitive flexibility, perturbed social behavior with reduced vocalization, and stereotypies at a low frequency [8]. Similarly, the IUGR offspring also developed neurobehavioral perturbations as an adult [45]. These changes may have their roots in altered embryonic development of neural cellular processes [51], which may have resulted or in turn have affected the neuronal glucose transport mediated by GLUT3. While it is difficult to quantify the neuronal glucose transport function in vivo, separate from the blood-brain barrier and glial GLUT1 $[6,7,59]$, one can surmise from in vitro experiments that a reduction in neuronal GLUT3, which activates adenosine monophosphate protein kinase, leads to diminution of ATP interfering with neurotransmission [12].

While the development of multiple neurotransmittory pathways is essential to affect normal neurodevelopment, for the purposes of this report, we focused primarily on serotonin that is derived from the essential amino acid tryptophan. We and others have previously demonstrated a reduction in tryptophan when maternal dietary/protein restriction is imposed $[60,61]$. Maternal tryptophan is essential for the early gestational serotonin-dependent neural networks [62]. Subsequently, the fetal brain innately produces serotonin, which is independent of ma- ternal amino acid metabolism [62]. Our present investigation demonstrates that fetal brain serotonin concentrations are also reduced in the presence of maternal caloric-restricted IUGR. Both GLUT3 and serotonin expression may be reduced in the IUGR due to changes in progenitor cell proliferative processes that have previously been observed to result in microcephaly at E19 [51]. Similarly, in our present study, we observed a reduction in head weights consistent with microcephaly. This diminution in serotonin was mirrored by a decrease in SERT concentrations, supporting a lack of maturation in the late gestation embryo of the adaptive upregulation that is seen subsequently [63].

Maternal HF dietary exposure has also been observed to result in a relative amino acid deficiency [64]. We noted that while maternal HF diet did not cause significant changes in serotonin and SERT concentrations in the embryonic brain, the trend toward a decrease particularly in serotonin along with a reduction in head weights (microcephaly) was concerning. We also assessed the impact of gestational exposure to air pollutants mimicking conditions of heavy traffic. Previous studies have revealed changes in fatty acid metabolism $[65,66]$ along with certain studies suggesting an association with diabetes mellitus and other related chronic disorders [67-69] upon close proximity to heavy traffic-related roadways. Furthermore, recent associations have revealed gestational exposure to AP reduced the ultrasound-assessed human fetal biparietal diameter [70-72], with the offspring subsequently developing ASDs [73-75]. Murine studies have demonstrated that exposure to volatile organic compounds perturbs adult brain serotonin concentrations affecting neurobehavior [76]. However, in our gestational mouse model, no significant effect was observed upon embryonic brain serotonin and SERT concentrations, although again a trend toward lower serotonin concentrations emerged. This observation suggests that perhaps other mechanisms besides serotonin alone are in play for changes related to gestational AP exposures, given that reduced fetal head weights (microcephaly) emerged.

In contrast, given that OXT is only produced by the hypothalamic paraventricular nucleus, we concentrated on OXTR that mediates inhibitory neurotransmission [77], opposing the excitatory activity of serotonin-SERT. Initially, similar to prior studies with cortical GLUT3 [5, 78] and that of others with brain serotonin-SERT investigations $[19,27,79]$, cortical OXTR also increased, with development peaking at a postnatal stage of P15, remaining constant thereafter into the adult stage. While E19 cortical OXTR was low, in a combination of IUGR male 
and female animals, no change in OXTR concentrations was seen. Teasing out male mice from female ones, albeit underpowered, revealed IUGR male mice to be more vulnerable than female mice. These results suggest that perhaps unlike the case of GLUT3 in adult brain [59], here, E19 IUGR male and female animals when separated showed similar changes in brain GLUT3. However, in IUGR brain serotonin-SERT, the possibility exists that the male mice are more vulnerable than female ones. Since we prospectively did not separate the male mice from female mice in serotonin-SERT analyses in particular, this is a limitation of our present study. It is quite possible that even in the HF and AP exposures, male mice were more affected than female mice, responsible for the overall decreasing trend in serotonin observed in the combination of sexes.

In our present study, we have demonstrated an imbalance between cerebral cortical serotonin and SERT concentrations early in life in response to maternal dietary modifications. These changes have the ability to affect brain plasticity and adaptation of the serotonergic neural networks [80] during their formative stages of embryonic development, with a lasting impact on adult neurobehavioral expression. In addition to these early life changes, we did not see any sex-specific changes in GLUT3 but have observed sex-specific changes in OXTR expression as early as during the embryonic phase of development. Our present embryonic investigations utilized the murine species since it was necessary to ensure that the role of the placenta was maintained intact in modulating the development of the embryonic GLUT and serotonergic pathways. The murine placenta which is hemochorial in nature is akin to that of the human placenta and has been widely characterized by us and others [81, 82]. Further, it is known that besides expressing GLUT1, GLUT3, and OXTR, placental TPH is essential for providing serotonin to the developing embryo [26]. We had examined the E19 placental SERT concentrations in response to maternal caloric restriction and observed undetectable amounts even in CON placentas (negative data were not shown).

The maternal calorie restriction model for producing IUGR is well established [82-84]. This model results in chronicity typical of human IUGR and as shown by us demonstrates a chronic reduction in uteroplacental blood flow [82]. In addition, this murine model has demonstrated a reduction in transplacental macronutrient fetal supply, culminating in growth-restricted embryos [82]. This calorie restriction is initiated during mid-gestation when brain de novo serotonin synthesis occurs, rather than early in gestation when the embryonic brain is fully reliant on placental transport and TPH conversion of tryptophan to an embryonic serotonin supply [26]. At near term (E19), embryonic brain serotonin and SERT concentrations were reduced, suggestive of reduced de novo synthesis of 5-HT, which in turn may have downregulated SERT expression levels. Such a change may adversely affect neural connectivity and plasticity of the developing mammalian brain $[19,21]$. In contrast, intrauterine exposure to a HF diet in the murine model led to enhanced intra-placental fatty acid (via CD36 protein) and glucose transport (GLUT1 protein) without much change in subtypes of amino acid transporters (SNATs and LAT2 proteins) [52]. Under such circumstances, embryonic brain serotonin and SERT concentrations remained unchanged with no significant perturbation, despite the decreasing trend in serotonin observed.

In various adult IUGR rodent studies, cerebral cortical concentrations of serotonin and SERT were found to normalize $[45,85,86]$; the perturbations experienced during the critical embryonic window of development are not seen. Thus, the impact of these embryonic perturbations on serotonin-dependent neural connectivity may have long-lasting effects on the brain [21], without displaying any neurotransmitter perturbations. While in this study, we did not undertake adult studies particularly defining neurobehavior, many others have studied the neurobehavior of the adult IUGR offspring or HF-exposed offspring and observed anxiety and hyperactivity in the former $[45,87,88]$ and depressive behaviors in the latter [89]. While there may be multiple factors contributing toward this ultimate neurobehavioral phenotype, our studies demonstrate a major role of maternal diet upon the early-life determinants of this ultimate phenotype. In addition, despite the normalization of either serotonin or SERT in the adult brain, various other perturbations related to activation of enhancers/modifiers, suppression of endogenous inhibitors, or other epigenetic factors can alter the serotonin-SERT pathway, resulting in altered availability or action of serotonin for neurotransmission $[21,29]$. Our observations where maternal dietary modifications perturb the 5-HT-5-HTT balance are reminiscent of the opposite impact of drugs such as selective serotonin reuptake inhibitors that increase the availability of synaptic serotonin for neurotransmission. Maternal serotonin reuptake inhibitors can easily cross the placenta and alter fetal brain serotonin availability [90], opposing what we detected with maternal dietary modifications.

Genetic mutations of the serotonin receptor isoforms (5-HT1B and 5-HT1D) have led to changes in fetal neural
38

Dev Neurosci 2021;43:27-42 DOI: $10.1159 / 000514709$
Ye/Shin/Baldauf/Ganguly/Ghosh/ Devaskar 
connections causing aberrant neurobehavior [25, 62]. While we have not assessed serotonin receptors in our present study, nongenetic environmental alterations in either serotonin or SERT or both impact the synaptic serotonin availability and function. Particularly during embryonic development ( $\sim \mathrm{E} 10.5)$, serotonin availability is necessary for neurogenesis, migration, and axonal development [19]. We have shown that dietary environments can cause an early 5-HT-5-HTT imbalance with the possibility of deranging neural/axonal development and synaptic connections. These derangements come with the propensity of long-term implications that adversely affect plasticity and adult neurobehavior [91]. More recently, mutations of SERT have been implicated in ASDs [15, 92], and circulating maternal serotonin concentrations have been associated with ASD in their offspring [93]. However, serotonin fails to cross the placenta [62], suggesting other indirect effects of these changes having implications for the developing embryo. It is known that male mice predominate in developing ASD [94], while female mice have a higher incidence of anxiety [95].

In conclusion, we have demonstrated that maternal dietary modifications (either low calories or high calories) alter fetal cerebral cortical neuronal GLUT, serotonin, and/or SERT concentrations, with not much of an effect on OXTR. While prenatal exposure to AP and maternal HF diet did not show significant changes, teasing out male mice from female ones may be important in future studies. These embryonic brain changes may underlie the development of anxiety and hyperactivity in the adult IUGR offspring [87, 88]. The molecular mechanisms tying early introduction of dietary modifications with the developing offspring's brain neurotransmitters is of significant importance, necessary for unraveling the pathogenesis of neurodevelopmental and mental health disorders. Such information may assist in targeted therapeutic interventions for these disorders after the fact, and prevention prior to the fact focused on optimizing maternal diet during pregnancy.

\section{Acknowledgments}

We thank Drs. James Waschek, PhD and Carlos Cepeda, PhD (Department of Psychiatry and Biobehavioral Sciences, UCLA) for their ongoing review and valuable insights.

\section{Statement of Ethics}

The authors, reviewers, and editors affirm that in accordance with the policies set by the Developmental Neuroscience Journal, this manuscript presents an accurate and transparent account of the study being reported and that all critical details describing the methods and results are present. Animal care or treatment was provided according to the UCLA Animal Research Committee-approved protocol in accordance with the guidelines set by the National Institutes of Health regarding the Care and Use of Laboratory Animals.

\section{Conflict of Interest Statement}

The authors declare that they have no competing financial interests.

\section{Funding Sources}

This work was supported by grants from the National Institutes of Health HD-081206 and HD-41230 (to SUD).

\section{Author Contributions}

Xin Ye performed the studies related to serotonin and SERT and wrote the first draft pertinent to this aspect of the manuscript, Bo-Chul Shin performed the studies related to GLUTs and OXTRs and wrote the first draft pertinent to this aspect of the manuscript, Claire Baldauf and Amit Ganguly created the maternal caloric restriction murine model used in this study, and Amit Ganguly also created the HF and exposure to AP murine models used in the study. Shubamoy Ghosh helped with the serotonin and SERT analysis. Sherin Devaskar provided the concept, designed the entire study, supervised the execution of the project, analyzed the data, and wrote parts of the paper in addition to reviewing and revising drafts of the manuscript.

\section{References}

1 Mergenthaler P, Lindauer U, Dienel GA, Meisel A. Sugar for the brain: the role of glucose in physiological and pathological brain function. Trends Neurosci. 2013 Oct;36(10): 587-97.

2 Dienel GA. Brain glucose metabolism: integration of energetics with function. Physiol Rev. 2019 Jan 1;99(1):949-1045.

3 Mitanchez D. [Ontogenesis of glucose regulation in neonate and consequences in neonatal

Brain Serotonin, SERT, and OXTR during Development management]. Arch Pediatr. 2008 Jan;15(1): 64-74.

4 Takata K, Hirano H, Kasahara M. Transport of glucose across the blood-tissue barriers. Int Rev Cytol. 1997;172:1-53.

5 Khan JY, Rajakumar RA, McKnight RA, Devaskar UP, Devaskar SU. Developmental regulation of genes mediating murine brain glucose uptake. Am J Physiol. 1999 Mar;276(3 Pt 2):R892-900.
6 Zheng PP, Romme E, van der Spek PJ, Dirven $\mathrm{CM}$, Willemsen R, Kros JM. Glut1/SLC2A1 is crucial for the development of the bloodbrain barrier in vivo. Ann Neurol. 2010 Dec; 68(6):835-44.

7 Tang M, Gao G, Rueda CB, Yu H, Thibodeaux $\mathrm{DN}$, Awano T, et al. Brain microvasculature defects and Glut 1 deficiency syndrome averted by early repletion of the glucose transporter-1 protein. Nat Commun. 2017 Jan 20;8:14152. 
8 Zhao Y, Fung C, Shin D, Shin BC, Thamotharan S, Sankar R, et al. Neuronal glucose transporter isoform 3 deficient mice demonstrate features of autism spectrum disorders. Mol Psychiatry. 2010 Mar;15(3):286-99.

9 Shin B-C, Cepeda C, Estrada-Sánchez AM, Levine MS, Hodaei L, Dai Y, et al. Neural deletion of glucose transporter isoform 3 creates distinct postnatal and adult neurobehavioral phenotypes. J Neurosci. 2018 Oct 31;38(44): 9579-99.

10 De Vivo DC, Leary L, Wang D. Glucose transporter 1 deficiency syndrome and other glycolytic defects. J Child Neurol. 2002 Dec; 17(Suppl 3):3S15-5; discussion 3S24-5.

11 Tang M, Park SH, De Vivo DC, Monani UR. Therapeutic strategies for glucose transporter 1 deficiency syndrome. Ann Clin Transl Neurol. 2019 Sep;6(9):1923-32.

12 Weisova P, Concannon CG, Devocelle M, Prehn JH, Ward MW. Regulation of glucose transporter 3 surface expression by the AMPactivated protein kinase mediates tolerance to glutamate excitation in neurons. J Neurosci. 2009 Mar 4;29(9):2997-3008.

13 Hajduch E, Rencurel F, Balendran A, Batty IH, Downes CP, Hundal HS. Serotonin (5-hydroxytryptamine), a novel regulator of glucose transport in rat skeletal muscle. J Biol Chem. 1999 May 7;274(19):13563-8.

14 Stapel B, Gorinski N, Gmahl N, Rhein M, Preuss V, Hilfiker-Kleiner D, et al. Fluoxetine induces glucose uptake and modifies glucose transporter palmitoylation in human peripheral blood mononuclear cells. Expert Opin Ther Targets. 2019 Oct;23(10):883-91.

15 Muller CL, Anacker AMJ, Veenstra-VanderWeele J. The serotonin system in autism spectrum disorder: from biomarker to animal models. Neuroscience. 2016 May 3;321:2441.

16 Nagano M, Takumi T, Suzuki H. Critical roles of serotonin-oxytocin interaction during the neonatal period in social behavior in $15 \mathrm{q}$ dup mice with autistic traits. Sci Rep. 2018 Sep 12; 8(1):13675.

17 Dolen G. Autism: oxytocin, serotonin, and social reward. Soc Neurosci. 2015;10(5):45065.

18 Hirosawa T, Kikuchi M, Ouchi Y, Takahashi $\mathrm{T}$, Yoshimura Y, Kosaka H, et al. A pilot study of serotonergic modulation after long-term administration of oxytocin in autism spectrum disorder. Autism Res. 2017 May; 10(5): 821-8.

19 Gaspar P, Cases O, Maroteaux L. The developmental role of serotonin: news from mouse molecular genetics. Nat Rev Neurosci. 2003 Dec;4(12):1002-12.

20 Sodhi MS, Sanders-Bush E. Serotonin and brain development. Int Rev Neurobiol. 2004; 59:111-74.

21 Daws LC, Gould GG. Ontogeny and regulation of the serotonin transporter: providing insights into human disorders. Pharmacol Ther. 2011 Jul;131(1):61-79.
22 Whitaker-Azmitia PM, Druse M, Walker P, Lauder JM. Serotonin as a developmental signal. Behav Brain Res. 1996;73(1-2):19-29.

23 Whitaker-Azmitia PM. Serotonin and brain development: role in human developmental diseases. Brain Res Bull. 2001 Nov 15;56(5): 479-85.

24 Whitaker-Azmitia PM. Behavioral and cellular consequences of increasing serotonergic activity during brain development: a role in autism? Int J Dev Neurosci. 2005 Feb;23(1): 75-83.

25 Bonnin A, Torii M, Wang L, Rakic P, Levitt P. Serotonin modulates the response of embryonic thalamocortical axons to netrin-1. Nat Neurosci. 2007 May;10(5):588-97.

26 Bonnin A, Goeden N, Chen K, Wilson ML, King J, Shih JC, et al. A transient placental source of serotonin for the fetal forebrain. Nature. 2011 Apr 21;472(7343):347-50.

27 Bruning G, Liangos O, Baumgarten HG. Prenatal development of the serotonin transporter in mouse brain. Cell Tissue Res. 1997 Aug; 289(2):211-21.

28 Moll GH, Mehnert C, Wicker M, Bock N, Rothenberger A, Rüther E, et al. Age-associated changes in the densities of presynaptic monoamine transporters in different regions of the rat brain from early juvenile life to late adulthood. Brain Res Dev Brain Res. 2000 Feb $7 ; 119(2): 251-7$

29 Brummelte S, Mc Glanaghy E, Bonnin A, Oberlander TF. Developmental changes in serotonin signaling: implications for early brain function, behavior and adaptation. Neuroscience. 2017 Feb 7;342:212-31.

30 Petraglia F, Imperatore A, Challis JR. Neuroendocrine mechanisms in pregnancy and parturition. Endocr Rev. 2010 Dec;31(6):783816.

31 Kim SC, Lee JE, Kang SS, Yang HS, Kim SS, An BS. The regulation of oxytocin and oxytocin receptor in human placenta according to gestational age. J Mol Endocrinol. 2017 Oct; 59(3):235-43

32 Napso T, Yong HEJ, Lopez-Tello J, SferruzziPerri AN. The role of placental hormones in mediating maternal adaptations to support pregnancy and lactation. Front Physiol. 2018; 9:1091.

33 Grinevich V, Desarménien MG, Chini B, Tauber M, Muscatelli F. Ontogenesis of oxytocin pathways in the mammalian brain: late maturation and psychosocial disorders. Front Neuroanat. 2014;8:164.

34 Boccia ML, Petrusz P, Suzuki K, Marson L, Pedersen CA. Immunohistochemical localization of oxytocin receptors in human brain. Neuroscience. 2013 Dec 3;253:155-64.

35 Freeman SM, Smith AL, Goodman MM, Bales KL. Selective localization of oxytocin receptors and vasopressin 1a receptors in the human brainstem. Soc Neurosci. 2017 Apr; 12(2):113-23.
36 Erbas O, Yilmaz M, Korkmaz HA, Bora S, Evren V, Peker G. Oxytocin inhibits pentylentetrazol-induced seizures in the rat. Peptides. 2013 Feb;40:141-4.

37 Dobolyi A, Kékesi KA, Juhász G, Székely AD, Lovas G, Kovács Z. Receptors of peptides as therapeutic targets in epilepsy research. Curr Med Chem. 2014;21(6):764-87.

38 Erfanparast A, Tamaddonfard E, HenarehChareh F. Intra-hippocampal microinjection of oxytocin produced antiepileptic effect on the pentylenetetrazol-induced epilepsy in rats. Pharmacol Rep. 2017 Aug;69(4):757-63.

39 Cai Q, Feng L, Yap KZ. Systematic review and meta-analysis of reported adverse events of long-term intranasal oxytocin treatment for autism spectrum disorder. Psychiatry Clin Neurosci. 2018 Mar;72(3):140-51.

40 Panaitescu AM, Isac S, Pavel B, Ilie AS, Ceanga $\mathrm{M}$, Totan $\mathrm{A}$, et al. Oxytocin reduces seizure burden and hippocampal injury in a rat model of perinatal asphyxia. Acta Endocrinol. 2018 Jul-Sep; 14(3):315-9.

41 Uzunova G, Pallanti S, Hollander E. Excitatory/inhibitory imbalance in autism spectrum disorders: implications for interventions and therapeutics. World J Biol Psychiatry. 2016 Apr;17(3):174-86.

42 Thompson JR, Valleau JC, Barling AN, Franco JG, DeCapo M, Bagley JL, et al. Exposure to a high-fat diet during early development programs behavior and impairs the central serotonergic system in juvenile non-human primates. Front Endocrinol. 2017;8:164.

43 Moreton E, Baron P, Tiplady S, McCall S, Clifford B, Langley-Evans SC, et al. Impact of early exposure to a cafeteria diet on prefrontal cortex monoamines and novel object recognition in adolescent rats. Behav Brain Res. 2019 May 2;363:191-8.

44 Ye W, Pitlock MD, Javors MA, Thompson BJ, Lechleiter JD, Hensler JG. The long-term effect of maternal dietary protein restriction on 5-HT1A receptor function and behavioral responses to stress in adulthood. Behav Brain Res. 2018 Sep 3;349:116-24.

45 Tomi M, Zhao Y, Thamotharan S, Shin BC, Devaskar SU. Early life nutrient restriction impairs blood-brain metabolic profile and neurobehavior predisposing to Alzheimer's disease with aging. Brain Res. 2013 Feb 7; 1495:61-75.

46 Yi L, Wei C, Fan W. Fine-particulate matter (PM2.5), a risk factor for rat gestational diabetes with altered blood glucose and pancreatic GLUT2 expression. Gynecol Endocrinol. 2017 Aug;33(8):611-6.

47 Zhang J, Zeng X, Du X, Pan K, Song L, Song W, et al. Parental PM2.5 exposure-promoted development of metabolic syndrome in offspring is associated with the changes of immune microenvironment. Toxicol Sci. 2019 Aug 1;170(2):415-26.

48 Costa LG, Chang YC, Cole TB. Developmental neurotoxicity of traffic-related air pollution: focus on autism. Curr Environ Health Rep. 2017 Jun;4(2):156-65. 
49 Chang YC, Cole TB, Costa LG. Prenatal and early-life diesel exhaust exposure causes autism-like behavioral changes in mice. Part Fibre Toxicol. 2018 Apr 20;15(1):18.

50 Nephew BC, Nemeth A, Hudda N, Beamer G, Mann P, Petitto J, et al. Traffic-related particulate matter affects behavior, inflammation, and neural integrity in a developmental rodent model. Environ Res. 2020 Apr; 183: 109242.

51 Baldauf C, Sondhi M, Shin BC, Ko YE, Ye X, Lee KW, et al. Murine maternal dietary restriction affects neural Humanin expression and cellular profile. J Neurosci Res. 2020 May; 98(5):902-20.

52 Ganguly A, Devaskar SU. High-fat diet affects pregestational adiposity and glucose tolerance perturbing gestational placental macronutrient transporters culminating in an obese offspring in wild-type and glucose transporter isoform 3 heterozygous null mice. J Nutr Biochem. 2018 Dec;62:192-201.

53 Chauhan V, Breznan D, Goegan P, Nadeau D, Karthikeyan S, Brook JR, et al. Effects of ambient air particles on nitric oxide production in macrophage cell lines. Cell Biol Toxicol. 2004 Jul;20(4):221-39.

54 Kurtz ML, Astort F, Lezon C, Ferraro SA, Maglione GA, Orona NS, et al. Oxidative stress response to air particle pollution in a rat nutritional growth retardation model. J Toxicol Environ Health A. 2018;81(20):1028-40.

55 Ganguly A, Collis L, Devaskar SU. Placental glucose and amino acid transport in calorierestricted wild-type and Glut3 null heterozygous mice. Endocrinology. 2012 Aug;153(8): 3995-4007.

56 Yano JM, Yu K, Donaldson GP, Shastri GG, Ann $\mathrm{P}, \mathrm{Ma} \mathrm{L}$, et al. Indigenous bacteria from the gut microbiota regulate host serotonin biosynthesis. Cell. 2015 Apr 9;161(2):264-76.

57 McFarlane L, Truong V, Palmer JS, Wilhelm D. Novel PCR assay for determining the genetic sex of mice. Sex Dev. 2013;7(4):207-11.

58 Ganguly A, McKnight RA, Raychaudhuri S, Shin BC, Ma Z, Moley K, et al. Glucose transporter isoform-3 mutations cause early pregnancy loss and fetal growth restriction. Am J Physiol Endocrinol Metab. 2007 May;292(5): E1241-55.

59 Dai Y, Zhao Y, Tomi M, Shin BC, Thamotharan S, Mazarati A, et al. Sex-specific life course changes in the neuro-metabolic phenotype of glut 3 null heterozygous mice: ketogenic diet ameliorates electroencephalographic seizures and improves sociability. Endocrinology. 2017 Apr 1;158(4):936-49.

60 Bhasin KK, van Nas A, Martin LJ, Davis RC, Devaskar SU, Lusis AJ. Maternal low-protein diet or hypercholesterolemia reduces circulating essential amino acids and leads to intrauterine growth restriction. Diabetes. 2009 Mar;58(3):559-66.
61 Calkins KL, Thamotharan S, Dai Y, Shin BC, Kalhan SC, Devaskar SU. Early dietary restriction in rats alters skeletal muscle tuberous sclerosis complex, ribosomal s6 and mitogenactivated protein kinase. Nutr Res. 2018 Jun; 54:93-104.

62 Bonnin A, Levitt P. Fetal, maternal, and placental sources of serotonin and new implications for developmental programming of the brain. Neuroscience. 2011 Dec 1;197:1-7.

63 Versteeg RI, Schrantee A, Adriaanse SM, Unmehopa UA, Booij J, Reneman L, et al. Timing of caloric intake during weight loss differentially affects striatal dopamine transporter and thalamic serotonin transporter binding. FASEB J. 2017 Oct;31(10):4545-54.

64 Edlow AG, Guedj F, Sverdlov D, Pennings JLA, Bianchi DW. Significant effects of maternal diet during pregnancy on the murine fetal brain transcriptome and offspring behavior. Front Neurosci. 2019;13:1335.

65 Salim SY, Kaplan GG, Madsen KL. Air pollution effects on the gut microbiota: a link between exposure and inflammatory disease. Gut microbes. 2014 Mar-Apr;5(2):215-9.

66 Miller DB, Ghio AJ, Karoly ED, Bell LN, Snow SJ, Madden MC, et al. Ozone exposure increases circulating stress hormones and lipid metabolites in humans. Am J Respir Crit Care Med. 2016 Jun 15;193(12):1382-91.

67 Bateson TF, Schwartz J. Who is sensitive to the effects of particulate air pollution on mortality? A case-crossover analysis of effect modifiers. Epidemiology. 2004 Mar;15(2): 143-9.

68 Coogan PF, White LF, Jerrett M, Brook RD, $\mathrm{Su}$ JG, Seto E, et al. Air pollution and incidence of hypertension and diabetes mellitus in black women living in Los Angeles. Circulation. 2012 Feb 14;125(6):767-72.

69 Cho J, Choi YJ, Suh M, Sohn J, Kim H, Cho SK, et al. Air pollution as a risk factor for depressive episode in patients with cardiovascular disease, diabetes mellitus, or asthma. J Affect Disord. 2014 Mar;157:45-51.

70 Smarr MM, Vadillo-Ortega F, Castillo-Castrejon M, O'Neill MS. The use of ultrasound measurements in environmental epidemiological studies of air pollution and fetal growth. Curr Opin Pediatr. 2013 Apr;25(2): 240-6.

71 Clemens T, Turner S, Dibben C. Maternal exposure to ambient air pollution and fetal growth in North-East Scotland: a populationbased study using routine ultrasound scans. Environ Int. 2017 Oct;107:216-26.

72 Malmqvist E, Liew Z, Källén K, Rignell-Hydbom A, Rittner R, Rylander L, et al. Fetal growth and air pollution: a study on ultrasound and birth measures. Environ Res. 2017 Jan; $152: 73-80$

73 Becerra TA, Wilhelm M, Olsen J, Cockburn M, Ritz B. Ambient air pollution and autism in Los Angeles county, California. Environ Health Perspect. 2013 Mar;121(3):380-6.
74 Weisskopf MG, Kioumourtzoglou MA, Roberts AL. Air pollution and autism spectrum disorders: causal or confounded? Curr Environ Health Rep. 2015 Dec;2(4):430-9.

75 Kerin T, Volk H, Li W, Lurmann F, Eckel S, McConnell R, et al. Association between air pollution exposure, cognitive and adaptive function, and ASD severity among children with autism spectrum disorder. J Autism Dev Disord. 2018 Jan;48(1):137-50.

76 Wang F, Fangfang Z, Guo X, Chen W, Yao W, Liu $\mathrm{H}$, et al. Effects of volatile organic compounds and carbon monoxide mixtures on learning and memory, oxidative stress, and monoamine neurotransmitters in the brains of mice. Toxicol Ind Health. 2018 Mar;34(3): 178-87.

77 Leonzino M, Busnelli M, Antonucci F, Verderio $\mathrm{C}$, Mazzanti $\mathrm{M}$, Chini $\mathrm{B}$. The timing of the excitatory-to-inhibitory GABA switch is regulated by the oxytocin receptor via KCC2. Cell Rep. 2016 Apr 5;15(1):96-103.

78 Thamotharan S, Stout D, Shin BC, Devaskar SU. Temporal and spatial distribution of murine placental and brain GLUT3-luciferase transgene as a readout of in vivo transcription. Am J Physiol Endocrinol Metab. 2013 Feb 1;304(3):E254-66.

79 Bruning G, Liangos O. Transient expression of the serotonin transporter in the developing mouse thalamocortical system. Acta Histochem. 1997 Mar;99(1):117-21.

80 Sbrini G, Brivio P, Bosch K, Homberg JR, Calabrese F. Enrichment environment positively influences depression- and anxiety-like behavior in serotonin transporter knockout rats through the modulation of neuroplasticity, spine, and GABAergic markers. Genes. 2020 Oct 23;11(11):1248.

81 Furukawa S, Kuroda Y, Sugiyama A. A comparison of the histological structure of the placenta in experimental animals. J Toxicol Pathol. 2014 Apr;27(1):11-8.

82 Ganguly A, Touma M, Thamotharan S, De Vivo DC, Devaskar SU. Maternal calorie restriction causing uteroplacental insufficiency differentially affects mammalian placental glucose and leucine transport molecular mechanisms. Endocrinology. 2016 Oct; 157(10):4041-54.

83 Chen PY, Ganguly A, Rubbi L, Orozco LD, Morselli M, Ashraf D, et al. Intrauterine calorie restriction affects placental DNA methylation and gene expression. Physiol Genomics. 2013 Jul 15;45(14):565-76.

84 Ganguly A, Chen Y, Shin BC, Devaskar SU. Prenatal caloric restriction enhances DNA methylation and $\mathrm{MeCP} 2$ recruitment with reduced murine placental glucose transporter isoform 3 expression. J Nutr Biochem. 2014 Feb;25(2):259-66. 
85 De Kloet ER, Kovács GL, Szabó G, Telegdy G, Bohus B, Versteeg DH. Decreased serotonin turnover in the dorsal hippocampus of rat brain shortly after adrenalectomy: selective normalization after corticosterone substitution. Brain Res. 1982 May 13;239(2):659-63.

86 Barr JL, Forster GL. Serotonergic neurotransmission in the ventral hippocampus is enhanced by corticosterone and altered by chronic amphetamine treatment. Neuroscience. 2011 May 19;182:105-14.

87 Lahti J, Räikkönen K, Pesonen AK, Heinonen K, Kajantie E, Forsén T, et al. Prenatal growth, postnatal growth and trait anxiety in late adulthood: the Helsinki Birth Cohort Study. Acta Psychiatr Scand. 2010 Mar;121(3):22735.
88 Mikaelsson MA, Constância M, Dent CL, Wilkinson LS, Humby T. Placental programming of anxiety in adulthood revealed by Igf2-null models. Nat Commun. 2013;4:2311.

89 Contu L, Hawkes CA. A review of the impact of maternal obesity on the cognitive function and mental health of the offspring. Int J Mol Sci. 2017 May 19;18(5):1093.

90 Olivier JD, Akerud H, Kaihola H, Pawluski JL, Skalkidou A, Högberg U, et al. The effects of maternal depression and maternal selective serotonin reuptake inhibitor exposure on offspring. Front Cell Neurosci. 2013;7:73.

91 Shah R, Courtiol E, Castellanos FX, Teixeira $\mathrm{CM}$. Abnormal serotonin levels during perinatal development lead to behavioral deficits in adulthood. Front Behav Neurosci. 2018;12:114.

92 Siemann JK, Muller CL, Forsberg CG, Blakely RD, Veenstra-VanderWeele J, Wallace MT. An autism-associated serotonin transporter variant disrupts multisensory processing. Transl Psychiatry. 2017 Mar 21;7(3):e1067.
93 Montgomery AK, Shuffrey LC, Guter SJ, Anderson GM, Jacob S, Mosconi MW, et al. Maternal serotonin levels are associated with cognitive ability and core symptoms in autism spectrum disorder. J Am Acad Child Adolesc Psychiatry. 2018 Nov;57(11):867-75.

94 Loomes R, Hull L, Mandy WPL. What is the male-to-female ratio in autism spectrum disorder? A systematic review and meta-analysis. J Am Acad Child Adolesc Psychiatry. 2017 Jun;56(6):466-74.

95 McLean CP, Asnaani A, Litz BT, Hofmann SG. Gender differences in anxiety disorders: prevalence, course of illness, comorbidity and burden of illness. J Psychiatr Res. 2011 Aug. 45(8):1027-35. 